\title{
FACTORS ASSOCIATED WITH THE QUALITY OF LIFE IN PATIENTS WITH EYE CANCER SURGERY
}

\author{
Trilaksana Nugroho'), Hari Peni Julianti²) \\ 1)Department of Ophthalmology, Faculty of Medicine, Universitas Diponegoro \\ 2)Department of Public Health-Preventive Medicine, Faculty of Medicine, \\ Universitas Diponegoro
}

Background: The World Health Organization (WHO) defines Quality of life (QOL) as an individual's perception of their position in life in the context of the culture and value systems in which they live, and in relation to their goals, expectations, standards and concerns. Visual impairment due to eye cancer has a negative impact on physical and mental health and well-being, therefore may have impact on patient quality of life. This study aimed to determine the factors associated with the quality of life in patients with eye cancer surgery.

Subjects and Method: This was a cross sectional study conducted at Dr. Kariadi Hospital, Semarang, Central Java. A sample of 32 patients post eye cancer surgery was selected for this study. The dependent variable was quality of life. The independent variables were age, sex, education level, income, and number of affected eyes. The quality of life data were measured by Short Form-36. The other data was collected by a questionnaire. Bivariate data analysis was performed by chi square, with odd ratio (OR) as the measure of association.

Results: After eye surgery, patients with one eye problem had better quality of life than those with two eyes problem $(\mathrm{OR}=3.41 ; 95 \% \mathrm{CI}=1.09$ to $7.83 ; \mathrm{p}<0.001)$. Sex $(\mathrm{OR}=1.11 ; 95 \% \mathrm{CI}=0.96$ to $1.28 ; \mathrm{p}=0.258)$, higher education level $(\mathrm{OR}=1.11 ; 95 \% \mathrm{CI}=$ 0.96 to $1.28 ; \mathrm{p}=0.258)$, and higher income $(\mathrm{OR}=1.11 ; 95 \% \mathrm{CI}=0.96$ to $1.28 ; \mathrm{p}=0.325)$ were associated with better quality of life, but it was statistically not significant. Older age $(\mathrm{OR}=0.90 ; 95 \% \mathrm{CI}=0.77$ to $1.04 ; \mathrm{p}=0.258)$ was associated with poorer quality of life, but it was statistically not significant.

Conclusion: Age, sex, education level, and income, are associated with quality of life in patients after eye surgery, although they are not statistically significant. Number of affected eye is associated with quality of life in patients after eye surgery, and it is statistically significant.

Keywords: quality of life, post surgery, eye cancer

Correspondence:

Trilaksana Nugroho. Department of Ophthalmology, Faculty of Medicine, Universitas Diponegoro Semarang, Central Java. Email: trilaks@yahoo.com. Mobile: 0811296047.

The $6^{\text {th }}$ International Conference on Public Health

Best Western Premier Hotel, Solo, Indonesia, October 23-24, 2019 | 363 https://doi.org/10.26911/the6thicph.05.28 